\title{
THEORY
}

\section{Making Inquiry Learning Our Top Priority: Why We Must and How We Can}

Carol Geary Schneider, Lumina Foundation

\begin{abstract}
The liberal arts of evidence-based inquiry are necessities for knowledgeable participation in a self-governing democracy and equally important in an innovation-dependent economy. Higher education's role in fostering these capacities has always been one of its most important contributions to the greater good. The current political environment calls for a new sense of urgency about preparing graduates to apply evidence-based reasoning to complex questions and competing claims. Yet a new study of students' coursebased assignments suggests that large numbers of college seniors are leaving college with a very weak grasp of how to use evidence or build a well-supported argument. Calling on educators to make the shift from "my course" to new intentionality about "our curriculum," the author provides practical suggestions for fostering the skills foundational to inquiry learning from first to final year.
\end{abstract}

Keywords: critical thinking; education outcomes; highimpact practices; inquiry-based learning

doi: $10.18833 /$ spur/1/1/10

Since you're reading this inaugural issue of SPUR, you're likely already convinced of the importance of undergraduate research. Sharing that conviction, I write here to urge you to now make it a top priority, not just to do a good job with those students who make their way into the research and inquiry learning zone, but to expand that inquiry learning zone until it includes every college student, whatever their interests, and whatever their background and preparation.

Today, we know from the National Study of Student Engagement (NSSE 2016) that about 45 percent of graduating seniors complete a "capstone project," which likely involves some kind of inquiry, writing, and/or another form of creative expression such as multimedia. My argument in this essay is that all students should both prepare for and participate in this kind of inquiry-framed culminating experience as a necessary part of their college studies. Whether students are headed for the world of work or further learning, their preparation for these culminating projects should, without exception, include schooling in the basics of research: problem framing, evidence-based inquiry, and engagement with multiple forms of evidence analysis and interpretation - both qualitative and quantitative.

In addition, to develop skills in evidence-based inquiry, all students should participate, every semester and every year, in complex assignments where they must grapple with the deployment of evidence-evidence drawn from other people's work, evidence drawn from their own inquiry learning, and evidence informed by experiences in negotiating the actual meaning and significance of findings with people whose views and standpoints are different from their own.

I urge you to provide strong leadership for inquiry-framed learning for two reasons. First, the capacity to make good use of evidence in tackling complex questions is necessary learning for a self-governing democracy in which "we the people" weigh in to make decisions about both leaders and policy choices. Similarly, the capacity to engage constructively with people, views, and values different from our own is a fundamental capability in a pluralist democracy. And yet, commitment to the importance of evidence has recently become endangered in U.S. society. 
Moreover, the whole concept of constructively and respectfully engaging diversity is, once again, under societal siege. Higher education needs to provide vocal and substantive leadership on these issues as our society works through them. More on that below.

Second, although higher education clearly should play a distinctive role in helping citizens hone the capacity to bring evidence and diverse perspectives to bear on complex questions, recent research indicates that higher education is falling significantly short of the mark in what is surely one of our most foundational responsibilities. New evidence on that front will be shared below as well.

If our society is to grapple successfully with complex questions, we need to promote, model, and teach the kind of mind-set required for complex decision-making. Crucially, we need to help our students do better. My work with educational reform over the past decades persuades me that a key way to "do better" is to involve students, early and often, in inquiry-based exploration of questions that matter, both to the students and to the wider society. This, in turn, will require a newly collaborative approach to the educational work of all postsecondary institutions. I provide some guiding premises for this work in the final part of this essay.

\section{My Journey to Inquiry-Based Learning}

As AAC\&U senior scholar Lee Knefelkamp (1990) reminds us, all educational thinking tends to be autobiographical. With this in mind, a brief review of my own history and experience with undergraduate research may help to clarify the assumptions and experiences that do-and do not-stand behind the proposals in this essay.

As a high school student and a Mount Holyoke College undergraduate, I did copious amounts of research. This began with a high school Advanced Placement course in American history, which included a long paper based on primary sources, and continued through to a thesis on Thomas More and Christian humanism in my final year of college.

I never did any of this work as part of a faculty member's research team. My research papers were almost all written to meet course assignments and expectations, both within and beyond my history major, an experience that strongly influences my belief that regular course assignments can and should build inquiry competence. The expectations for my "research productivity" seemed to grow markedly across my four years of college so that, in my junior year alone, I turned in more than 200 pages of completed writing, most of it in the form of 20-30 page research papers and a separate set of shorter literature reviews. In addition, anticipating my senior thesis and feeling anxious about my ability to succeed in such a big project, I also undertook a credit-bearing "independent study" in my sophomore year.
A lot of this research was not, in fact, very good, especially the work from my first two years of college. Much of my early college work was descriptive and derivative rather than analytical or insightful. Nonetheless, constant practice did build skill, and my senior thesis was a creditable piece of work, grounded in the writings of More and Erasmus, informed by mentored independent reading in Plato (a major influence on Christian humanists), and enriched by a deep dive into the extensive and conflicting secondary literature on my subjects.

What did I gain from these efforts? By the time I graduated from college, I was already well aware that I had internalized a strong sense of the difference between really knowing what I was talking about on a complicated topic and "just winging it" with quickly acquired and unexamined opinion. That knowledge has stood me in good stead over a long career. It was, among other benefits, a critically important job skill. Not least, it inclined me toward an extended family of colleagues and fellow leaders whose own expert knowledge on specific topics could complement and supplement the unavoidable limits on my own (or any single person's) deep learning bandwidth.

My acquired disinclination to "just winging it" also has helped me as a citizen. We cannot all be experts on every subject. But we can develop working criteria for the professed expertise of others. We can ask of public leaders what Mount Holyoke and (later) Harvard University asked of me: a commitment to deep engagement with complexity and a resistance to shallow, once-over-lightly opinion.

Much as I value what I gained from my education, when I propose that every student should prepare for and participate in a significant inquiry-based learning project, my own highly academic training is decidedly not what I have in mind. The kind of pre-graduate school apprenticeship I experienced in college is appropriate for some students but surely not for all or even most.

What I do have in mind is students' constant engagement with-and evidence-based writing about-unscripted questions-questions where the right answer is not known and where students will have to do significant work to develop a reasoned and evidence-supported judgment. Optimally, many of these assignments will involve questions that interest the student actually doing the work and problems whose significance the student will learn to clarify for others. Inevitably, many of these questions will involve controversies about the best course of action, with some of these controversies inflected-directly (through studies of social change) or implicitly (through the dynamics of a lab, workgroup, or social media) - by issues of power, identity, and equity. 
These commitments to inquiry-based learning and the practices that help students master it were front and center during my most far-reaching work as president of AAC\&U: the long-term and still-continuing Liberal Education and America's Promise initiative (LEAP; AAC\&U 2015 ) to provide a contemporary guiding vision for liberal education in a complex global world. LEAP focuses on a set of "essential learning outcomes" - such as critical thinking, problem-solving, intercultural learning, ethical reasoning, and communicating - that are important in every field of endeavor, from the workplace to democratic community and scholarship.

LEAP also helped develop and promulgate evidence that students are most likely to develop these essential capacities when they participate frequently in hands-on educational experiences-first-year seminars, research experiences, writing-intensive courses, collaborative projects, diversity learning, senior capstones, and the likethat require them to grapple with complex questions and with competing perspectives on those questions.

Since 2007, these kinds of hands-on inquiry learning experiences have been recognized as high-impact practices or HIPs. Evidence from NSSE gathered over the past decade shows compellingly that when students participate in HIPs, they are more likely to make progress on expected learning outcomes, and more likely to persist in and complete their college studies (Kuh 2008; Brownell and Swaner 2010; Kuh, O'Donnell, and Schneider 2017). Other studies show that the more frequently students participate in HIPs, the better the results, again both for completion and deep learning (Finley and McNair 2013).

Space does not permit a recapitulation here of the large and growing literature on HIPs. My argument here is that inquiry-based learning, grounded in recurrent engagement with evidence and diverse perspectives on the meaning of evidence, can give purpose and focus to educators' use of HIPs, including undergraduate research, to increase both students' persistence in college and achievement of essential learning outcomes.

Rather than seeing participation in various HIPs as a new set of boxes for students to "check off," we can stage those experiences in ways that build students' meaningful engagement with questions they care about and that prepare them for the culminating HIP: completion of capstone work that reflects and expresses their development as capable, inquiry-centered learners. AAC\&U has incorporated this concept in its ongoing LEAP campaign through the recently released LEAP Challenge: a call to include multiple experiences with HIPs and a culminating signature work experience in every student's journey through college (AAC\&U 2015; Schneider 2015; Peden, Reed, and Wolfe 2017).
Whereas today slightly less than half of all students report doing culminating work in their final year, The LEAP Challenge invites higher education to make such projects the new standard for quality college learning. The term signature signals that, in this effort, students will take ownership of their work, choosing topics they care about and preparing to share the fruits of their work with others.

Although the concept of a culminating inquiry project for all students may seem a daunting reach today, adopting this reform would in fact accelerate a trend toward involving students in "capstone" work that has been visible for more than two decades across all parts of higher education (Schneider 2004, 2015). It would also bring energy to yet another discernible education trend: campus efforts to help students integrate the different aspects of their college study: broad and specialized learning, experiential and formal learning, and intellectual skills deployed "across-the-curriculum."

Research on campus educational priorities shows that the majority of postsecondary institutions already are working to provide more integrative forms of college learning for today's students (Hart Research Associates 2015a). Expecting and preparing college students to tackle a complex inquiry question or problem in a senior project would bring new educational and organizational focus to this work on integrative learning. Moreover, if faculty and advisers bring students' own questions and interests directly into their educational preparation for capstone work, integrative inquiry learning can become motivating to students themselves, because it will focus by design on issues that students really want to engage and explore (Schneider 2016).

Employers strongly endorse the idea that students should do significant projects as undergraduates. Some 73 percent of employers recently indicated that requiring students to do a significant project would improve their preparation for careers. Moreover, 87 percent of employers indicated that they would be more likely to hire a student who had completed "an advanced, comprehensive project in senior year, such as a thesis, senior project or other major assignment that requires the student to demonstrate depth of knowledge in their major AND their acquisition of research, problem-solving, and communication skills" (Hart Research Associates 2015b, emphasis in original).

\section{The New Urgency Around Using Evidence}

As the discussion here makes clear, my commitment to the value of evidence-based inquiry is long-standing and rooted in emerging findings about "what works" educationally for today's students. What is new today, however, is my dramatically heightened sense of civic urgency about the need to move students' engagement with inquiry, 
evidence, and diverse perspectives to the very top of the higher education reform agenda.

The first driver for this new urgency is the suddenly fierce debate in our society over what seems an almost surreal issue: the question of whether our public policy choices will be anchored in evidence or whether they will be driven by arbitrary assertions that run counter, not only to prevailing expert judgment but also to decades of persuasive quantitative data. Here are just three examples from dozens that might be cited: the willful denial, at the highest levels of our government, of the prevailing consensus on global warming and its increasingly evident deleterious consequences; federal policy, again at the highest levels of government, that presumes a crisis in law enforcement when reported crime levels are actually at all-time lows over the past quarter century; or the claim that deep tax cuts will be new revenue generators when three decades of earlier experiments with this idea show that a deep cut in taxes invariably results in deeper deficits. In each of these instances, the "facts" run directly counter to leaders' political priorities. Yet in the roiling world of U.S. politics, such inconvenient truths are very readily dismissed while the "elites" who keep insisting on evidence are themselves assailed as untrustworthy.

There is even a new term for this phenomenon: national leaders who dismiss expert findings are being guided instead by "alternative facts." Arrestingly, almost as soon as the notion of "alternative facts" went viral in late January 2017, CNN reported that George Orwell's 1984, which deals with the distortion of language in a dystopian regime, had surged unexpectedly to the top of Amazon's computer-generated bestseller list.

Clearly, many are alert to the dangerous assault on evidence. And yet, as one analyst has observed in commentary about similar developments in France, disruptive leaders operate freely in this new zone of "alternative facts" because "it works: Voters today don't read long analyses," this analyst notes, "they remember forceful assertions" (Daoud 2017). Indeed, if baseless but forceful assertions are made with enough frequency, the strategy simply overwhelms factchecking or follow-up on what actually happened. The public registers the strong assertion of a position. The factfree position, stated with sufficient frequency, becomes "normalized." Only the dogged take the trouble to discern the disconnect among assertion, evidence, and long-term impact. Their investigations have little effect in correcting the dominant narrative.

Self-evidently, the whole concept of choosing one's own facts flies directly in the face of higher education's most fundamental commitments: to the honest search for new and verifiable knowledge and to the multifaceted examination of difficult questions where values and diverse contexts necessarily influence what we come to hold as knowledge. Yet it is all too easy in our contemporary context where "elites" are perceived as the problem for leaders to despair of any hope that we can educate fellow citizens to prefer complexity and to resist simplistic assertions and invented "information." Rather, educators are being told it is time to listen with new attentiveness to those who have been left behind, both from opportunity and a solid education, so that we ourselves can learn with new humility.

This is indeed a time for thoughtful reassessment by everyone who cares about the future of democracy. But it is also a time for recommitting to core values and for asking how we can better align our practices with those values.

Whatever our current political travails and soul-searching, higher education is today, and always has been, a dedicated space where scholars, leaders, and learners come together to explore complexity and to seek the kind of knowledge that helps build a better world. We cannot retreat from this mission; we must band together both to forcefully reaffirm it and to expand our communities so that ever larger numbers of students can benefit from the empowerment provided by inquiry learning. And, as I suggested in the first part of this essay, we can expand our conception of "questions that matter" so that community concerns and our own students' concerns become catalysts for deep inquiry as well as collaborative, inclusive, and generative problem-solving.

Evidence matters, we must vigorously affirm, and higher education's two most fundamental obligations are to advance the search for evidence-based understanding and to help learners develop their own capacities for reasoned judgment in the face of complexity. These are democracy fundamentals which are equally needed in an innovationfueled knowledge economy.

The work we do best is everyone's best hope for a better future. We need to proclaim, expand, and enact that conviction. At all levels - from the boardroom to the classroom, in person and via social media - we need to see a new, concerted affirmation from higher education that the advancement of knowledge through evidence-based inquiry is foundational to a great democracy and that we play a special and irreplaceable role, both in teaching students (and future scholars) how to evaluate competing knowledge claims and in teaching respect for the importance of diverse voices and perspectives in all such evaluation.

\section{To Our Peril, Today's Students Are Falling Short on Inquiry Skills}

Thus far, I have argued the following: evidence matters. It is indispensable to virtually any question we aim to solve. Higher education leaders need to profess and proclaim our special role in helping students develop both 
the capacity and the commitment to deploy evidence from diverse sources and to engage differing perspectives on the meaning of evidence.

Research experiences are part of this special role. But so, too, are other forms of learning: inquiry seminars; linked courses in which students explore a complex topic across different disciplines and assignments; field-based learning; collaborative projects; diversity and global experiences; creative work and collaborations; and ePortfolios that foster reflection as well as synthesis of students' learning over time (Kuh 2017; Eynon and Gambino 2017). We can and must foreground and showcase the multiple forms of inquiry-based learning that prepare students to contribute both as citizens and in a fast-changing workplace.

Yet even as we rally to reaffirm the importance of inquiry learning, there is a second driver behind my proposal that inquiry learning needs to become higher education's most urgent priority: specifically, the mounting evidence that large numbers of graduating students are falling well short of the mark when it comes to critical inquiry, the analysis of evidence, and the engagement of diverse perspectives in the interpretation of evidence. Committed though higher education may be to inquiry as its most important public good, new research shows that students are significantly underperforming on core skills - including the use of evidence and engagement with diverse perspectivesthat are foundational to critical inquiry. This would be bad news at any time. It is especially bad news at a moment when the nation sorely needs all the talent it can bring to creating evidence-based solutions to pressing public and economic problems.

Until very recently, the only national studies of college students' prowess with critical thinking skills were based on standardized tests that have been disconnected by design from the work done by students in the context of their day-to-day college courses. Today, however, higher education has new assessment tools that allow a deep dive into evidence drawn directly from students' completed course assignments about their skills in the learning outcomes that most educators will agree are "essential." For the first time, we are poised to form judgments about students' achievement levels based not on tests that are disconnected from the curriculum but directly on work they initially completed to earn course grades.

This assessment strategy is called Valid Assessment of Learning in Undergraduate Education (VALUE; AAC\&U 2017b). The tools are VALUE rubrics, which are keyed to 16 widely endorsed goals for college learning, ranging from the most obvious (such as critical thinking, communication, or quantitative reasoning) to less commonly studied outcomes (such as problem-solving, intercultural learning, ethical reasoning, integrative learning, and global learning). Created to help educators assess student progress on the LEAP Essential Learning Outcomes, the rubrics were initially developed through grants from the Fund for the Improvement of Postsecondary Education of the U.S. Department of Education and State Farm Companies Foundation.

The VALUE rubrics are the work of faculty teams from all parts of higher education, including experts in each of the learning outcomes being assessed. The rubrics were validated by other faculty members, who used initial and revised versions of the rubrics to assess samples of student work drawn from across the curriculum. The advantage of this approach to assessment over standardized tests is that faculty members using it become directly engaged with the question whether the assignments being given to students are really appropriate to help foster the capacities we believe students need to achieve. The VALUE approach helps shift faculty attention away from "what I do in my course" to how well "our curriculum" is actually fostering essential learning outcomes.

Initially, the VALUE rubrics were used campus by campus or even department by department, making it difficult to draw more general insights about student progress from these assessments. Today, however, there is an organized effort across higher education to develop VALUE assessments systemically, using trained faculty scorers, common rules for choosing assignments that are appropriate for the learning outcomes under review, and a national digital platform through which faculty can assess the levels of demonstrated skills in student assignments from campuses other than their own. Altogether, there are nearly 100 institutions - public and private, two- and four-yearinvolved in the ongoing national VALUE study.

This demonstration VALUE study is the result of several years of collaboration among AAC\&U, the State Higher Education Executive Officers Association (SHEEO), the Multi-State Collaborative to Advance Quality Student Learning (MSC) that now includes 13 state systems or coordinating boards, the Great Lakes Colleges Association (GLCA), and a Minnesota Collaborative that involves public and private higher education institutions. The current funding for this effort has come from multiple sources, including the Bill and Melinda Gates Foundation, the Spencer Foundation, the Sherman Fairchild Foundation, and Lumina Foundation.

This ongoing effort has released two sets of findings, one in 2015 from a pilot year, undertaken to test protocols for the study, and a second set in spring 2017 from the socalled demonstration year. Findings from the pilot-year study can be found at http://www.aacu.org/press/pressreleases/multi-state-collaboration-produces-valuable-newevidence-about-writing-critical. The demonstration-year 
results are reported in detail in On Solid Ground: A Preliminary Look at the Quality of Student Learning in the United States (AAC\&U 2017a). Additional aspects of the study are reported by SHEEO (2017).

In what follows, I call readers' attention to the 2017 findings reported by the MSC - the largest group of two- and four-year institutions in the VALUE study-for student achievement in critical thinking and especially its five components: (1) the student's explanation of issues, (2) use of evidence, (3) ability to engage the context/assumptions embedded in the issue being explored-in effect, how well both context and multiple perspectives are engaged in the issue under study, (4) position (perspective, thesis, hypothesis); and (5) development of conclusions/outcomes based on an analysis of both evidence and perspectives. The findings come from 34 public two-year colleges and 41 public four-year institutions, including public research universities.

The assignments used to reach conclusions on critical thinking capacities were drawn from students who had completed three quarters of their degree program-more than 45 hours at the associate level or more than 90 hours at the baccalaureate level. The faculty members who evaluated those assignments had undergone training to ensure consistency and reliability in their application of the relevant VALUE rubrics. The assignments came from a broad range of disciplines, and all scorers came from institutions other than the students' home campus.

The results for college seniors (based on 2056 samples of student work drawn from institutions in 12 states) reveal that only a few of their assignments were scored at level 4-that is, met the "capstone level" of proficiency on the VALUE rubric for specific dimensions of critical thinking. Here are the findings on assignments that met level 4 standards for different aspects of critical thinking:

- 11 percent on explanation of issues,

- 5 percent on use of evidence,

- 6 percent on context/assumptions,

- 6 percent on position (perspective; thesis; hypothesis), and

- 7 percent on conclusions/outcomes (see Figure 1).

If the scores of seniors who reached either level 3 or level 4 on these component dimensions of critical thinking are added together, the results show that only a third or fewer of the assignments demonstrated proficiency at level 3 or level 4 for the components of critical thinking shown in Figure 1 except explanation of issues.

Moreover, the two-year scores - all drawn from students in community colleges who had completed more than 45 hours - reveal that approximately half to two-thirds of the two-year students are scoring at or above level 2, whereas two-thirds to three-quarters of the seniors are not reaching even level 3 on any aspect of critical thinking except explanation of issues (see Figure 1). This raises the question whether the assignments that students receive in their final two years are really aiming at higher level intellectual skills. VALUE leaders are currently probing this critical question (AAC\&U Vice President Terrel Rhodes, email message to author, May 2017).

Seniors did somewhat better against the VALUE rubric for communication (AAC\&U 2017a, 39), with half or more reaching at least level 3 on most dimensions of the

FIGURE 1. Critical Thinking

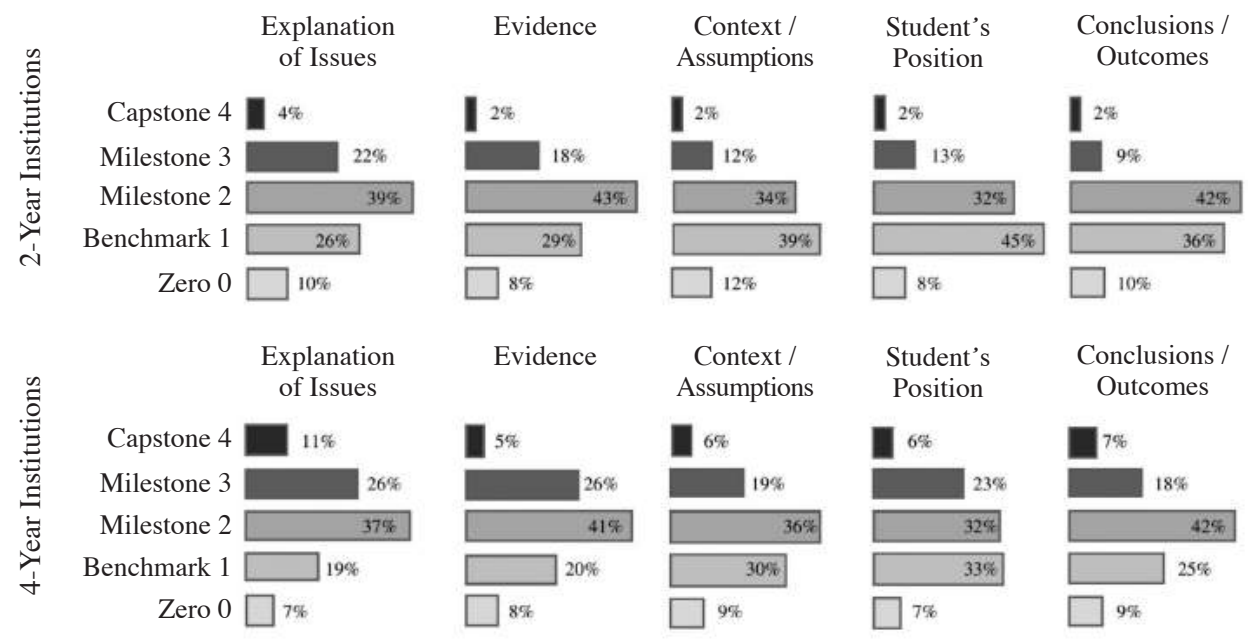

Note: Assignments scored for the VALUE study came from students who completed $75 \%$ of their studies for the associate degree or for the bachelor's degree. The assignments came from a broad range of courses and disciplines. Figure reprinted with permission from On Solid Ground, copyright (C) 2017 by the Association of American Colleges and Universities.

50 Scholarship and Practice of Undergraduate Research 
learning outcome. But here, too, the results indicate that many of students are not reaching expected standards of proficiency when it comes to the use of sources/evidence. Only 13 percent of senior assignments scored for this study reached level 4 on the dimension of sources/evidence, with another 29 percent reaching level 3.

In other words, the assignments initially submitted by these students for course grades showed that nearly 6 in 10 seniors were at a preliminary level only in their capacity to use evidence in the context of a written communication.

Leaders of the VALUE project caution that these findings should not be generalized beyond the institutions in the VALUE studies - in this case, the 75 institutions participating in the MSC collaborative (AAC\&U 2017a, 33). Even with that stipulation, the VALUE results are nonetheless sobering. Research conducted for AAC\&U in 2015 shows that fully 98 percent of member institutions have made critical thinking one of their expected learning outcomes, with 99 percent also making communication one of their core expectations for student achievement (Hart Research Associates 2015a). Other research shows that employers consider critical thinking one of the basics for success in the workplace (e.g., Hart Research 2015b). Moreover, as argued above, evidence-based thinking is equally fundamental in a self-governing democracy. Yet the evidence drawn from students' own work shows that too many graduating students are not reaching the expected inquiry-learning proficiency.

In a way, these findings should not be surprising. Survey research shows that employers also give recent graduates low marks on such fundamentals as critical thinking, communication, and diversity acumen (Hart Research Associates 2015a). But most faculty members do not view employers as the ultimate source of evidence on the quality of student learning. In the VALUE study, findings have been produced by faculty members themselves based on assignments initially prepared to fulfill course requirements.

What the VALUE evidence shows is a troubling distance between the aspirations of higher education and the actual outcomes for students. To serve both students and society, educators must close that gap.

\section{How to Address the Inquiry Learning Gap}

What, then, do we do? Higher education's commitment to inquiry - both as scholarship and as a critical dimension of student learning - needs not just vigorous reaffirmation but a comprehensive and determined "do-over."

That do-over should begin, I suggest, with a new focus on collaborative planning-informed by local assessments of students' authentic work - to ensure that the courses taught really do engage students, early and often, and at progressively more challenging levels, in assignments that require the component elements of inquiry learning: framing a question, engaging diverse perspectives drawn from different contexts on that question, examining and/ or developing evidence, making an evidence-based judgment, and examining the limitations or likely dissents to a personal position.

The general idea is that faculty responsible for a program of study can and should ensure that regular course assignments in that program do the following:

1. engage the student with significant questions that matter to the student as well as to others;

2. establish engagement with inquiry and evidence as essential;

3 . help each student develop the capacity and the commitment to engage both diverse perspectives and the value of evidence in tackling complex questions; and

4. enable students to take ownership of their own learning, in full understanding that continued learning will be absolutely necessary in all parts of their lives - as employees in the workplace, as residents of a community, and as resilient human beings.

This does not mean that every course needs to address every expected learning outcome or every component of a complex learning outcome such as critical thinking or communication. But it does mean that every faculty member and student should know where, when, and how students will work across different courses to develop the multiple capacities necessary to engage in inquiry, analysis, invention, problem-solving, and communication. This is by no means a constraint on course content or teaching approaches to that content. But it does call for a new degree of intentionality about ensuring, across multiple courses, that students will complete content-appropriate intellectual tasks related to the different elements of inquiry learning.

As both my own experience in college and the results of the VALUE study suggest, assignments are the critical key to students' development of proficiency. When the assignments are weak or when, in a misplaced expression of "academic freedom," a course includes no assignments at all, the chance that students will become proficient in complex analysis is remote. Thus assignments need to be collaboratively and intentionally planned, with faculty members helping one another-and consulting national research-on the kinds of activities that help students become proficient inquiry learners.

Today, on virtually every campus, course assignments remain each faculty member's private decision. This is the Achilles heel that frustrates achievement of our highest educational purposes. 
Making assignments a form of community property is likely the most important thing we can do to ensure that students have equitable access to inquiry learning experiences and guided development of their most important intellectual skills. As previously mentioned, the ultimate assignment should be the student's capstone or signature work-a complex project, taking at least a semester to complete, that reflects each student's interests and developed ability to bring inquiry skills and judgment to the final project.

Table 1 provides a curriculum "map" that shows how faculty together can plan for, and help students prepare for, both proficiency in inquiry learning and completion of a capstone or signature work project. The "map," which has been amended from a model freely available on the web, shows where and how often students would practice specific inquiry capacities in the context of their study in a particular academic area. The map could be further amended to track general education goals and practices from first to final year.

What needs to be stressed, however, is that this "map" remains a profile, an outline. It will come to educational "life" only when faculty reach shared agreement on the kinds of assignments that will successfully build both the discipline-specific learning they value in their programs and the capacity to use cross-cutting skills such as evaluating evidence or engaging/applying diverse perspectives in ways appropriate to the field of study.

I am mindful that many faculty teach so many students in a given semester that they consider it impossible to give robust assignments or even examinations that go beyond multiple-choice responses. I am also mindful that many faculty members teach "outside" any meaningful curriculum dialogue because they are adjunct rather than full-time members of the community.

These are significant but not insurmountable obstacles. They seem impossible mainly because typical campus practice leaves each faculty member essentially on his or her own to determine his or her role in fostering students' intellectual development.

Even in large courses, there are many things faculty can do to involve students in inquiry learning assignments. For example, they can offer collaborative rather than individual student projects; enlist well-prepared advanced students as undergraduate learning assistants to coach novice students in inquiry and problem-solving strategies (Ehrmann 2017); or provide flipped classrooms, in which students review lecture materials in advance and work actively together on mini-assignments in class. José Bowen and C. Edward Watson's Teaching Naked Techniques (2017) provides a rich family of examples drawn from faculty members teaching in all kinds of institutions across the
United States. Its discussion of "integrative learning" is especially useful to those engaged in program planning that fosters deeper student engagement in inquiry learning.

For adjuncts, the curriculum mapping exercise illustrated in Table 1 can be especially useful to their teaching, even if they are not available to take part in the mapping exercise. Seeing - via a program curriculum map-how their courses fit into a larger educational trajectory brings part-time faculty into a shared community of practice. Knowing the kinds of assignments expected in their particular course(s) frees adjuncts from the isolated exercise of deciding almost entirely on their own how much they should ask of their students. Once the program itself becomes highly intentional, adjuncts can see far better how "my course" fits into "our curriculum" and their own role in the students' development as inquiry-proficient learners.

My main recommendation here is that members need to work together on mapping inquiry learning across the educational trajectory instead of leaving each faculty member to do his or her best in the absence of any shared planning. Conceivably, faculty will come to a consensus that some courses will be content heavy with few or no assignments beyond examinations. But they also need to organize their collective time so that every program includes sequences of learning activities, from first to final level, that ensure students' equitable access to quality assignments designed to take them to high levels of proficiency on all the components of evidence-based reasoning. Most institutions still distinguish, on the books, between 100-level courses, 200level courses, and so on. The question to ask is what kind of assignments should be done by students at each level so that, whatever content they study, all will build skill both in the basics of inquiry and in the translation of their own questions into meaningful projects.

The curriculum map in Table 1 can open faculty discussions. But the larger goal is a curriculum design that is regularly revisited to determine its effectiveness. The work produced by students for their assignments, including their culminating assignments, will show faculty what is working and what still needs amendment.

This kind of faculty collaboration becomes even more important in considering the impact of digital innovation on mainstream higher educational practice. It is clear that the digital revolution has already significantly changed the way many students learn and that the future will bring new combinations of digitally supported, face-to-face, and blended forms of learning. The question to pursue now (a form of inquiry learning in its own right) is how faculty can use digital platforms to help free up time and space so they can help students build the knowledge, skills, and mentored experiences needed to deal successfully with unscripted, open-ended problems (Bass and Eynon 2016). 


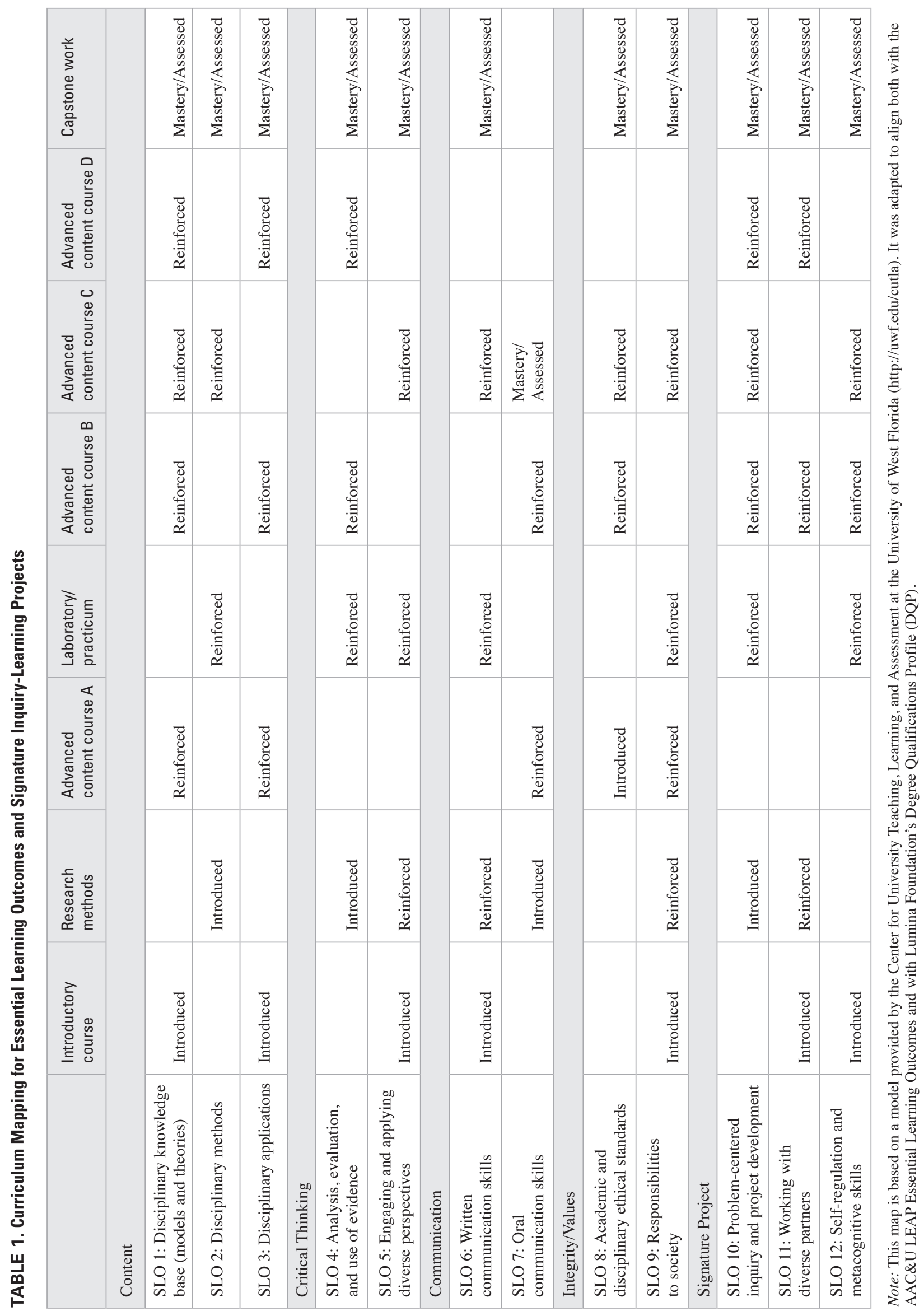


Mentoring student work is time-consuming and challenging. Faculty need to ask, therefore, how digital platforms and cognitive tutorials can be employed to release them from such tasks as lecturing so that time can be reassigned to the kinds of learning from which students will gain the most long-term value.

These are not simple questions, but this is the time to ask and answer them. Higher education must rally to ensure that it provides more-and more empowering-inquiry learning for today's students. Anything less will shortchange our students and deplete democracy's future.

\section{References}

Association of American Colleges and Universities. 2015. The LEAP Challenge: Education for a World of Unscripted Problems. Washington, DC: Author.

Association of American Colleges and Universities. 2017a. On Solid Ground: A Preliminary Look at the Quality of Student Learning in the United States. Washington, DC: Author. Accessed April 1, 2017. http://www.aacu.org/OnSolidGroundVALUE

Association of American Colleges and Universities. 2017b. VALUE. Washington, DC: Author. Accessed July 28, 2017. http:// www.aacu.org/value

Bass, Randy, and Bret Eynon. 2016. Open and Integrative: Designing Liberal Education for the New Digital Ecosystem. Washington, DC: Association of American Colleges and Universities.

Bowen, José A., and C. Edward Watson. 2017. Teaching Naked Techniques: A Practical Guide to Designing Better Classes. San Francisco: Jossey-Bass.

Brownell, Jane E., and Lynn E. Swaner. 2010. Five High Impact Practices: Research on Learning Outcomes, Completion, and Quality. Washington, DC: Association of American Colleges and Universities.

Daoud, Kamel. 2017. "The French Disconnection.” New York Times, April 21, A25.

Ehrmann, Stephen C. 2017. "Improving Course OutcomesUses of Undergraduate Learning Assistants." Accessed April 1, 2017. http://sehramm.blogspot.com/2017/06/improving-courseoutcomes-impact-of-html

Eynon, Bret, and Laura M. Gambino. 2017. High-Impact ePortfolio Practice: A Catalyst for Student, Faculty, and Institutional Learning. Sterling, VA: Stylus. Ebook.

Finley, Ashley, and Tia McNair. 2013. Assessing Underserved Students' Engagement in High-Impact Practices. Washington, DC: Association of American Colleges and Universities.

Hart Research Associates. 2015a. National Trends in General Education Design, Learning Outcomes, and Teaching Approaches. Washington, DC: Association of American Colleges and Universities.

Hart Research Associates. 2015b. Falling Short? College Learning and Career Success. Report on a Survey of Employers. Washington, DC: Association of American Colleges and Universities.

54 Scholarship and Practice of Undergraduate Research
Knefelkamp, L. Lee. 1990. "Seasons of Academic Life: Honoring Our Collective Autobiography." Liberal Education 76(3): 4-12.

Kuh, George D. 2008. High-Impact Educational Practices: What They Are, Who Has Access to Them, and Why They Matter. Washington, DC: Association of American Colleges and Universities.

Kuh, George D. 2017. “And Now There Are 11.” Foreword to Eynon and Gambino.

Kuh, George D., Ken O’Donnell, and Carol Geary Schneider. 2017. "HIPs at Ten." Change: The Magazine of Higher Learning 49(5).

National Survey of Student Engagement (NSSE). 2016. Engagement Insights: Survey Findings on the Quality of Undergraduate Education-Annual Results 2016. Bloomington: Center for Postsecondary Research, Indiana University School of Education.

Peden, Wilson, Sally Reed, and Kathy Wolfe. 2017. Rising to the LEAP Challenge: Case Studies of Integrative Pathways to Student Signature Work. With a foreword by Lynn Pasquerella. Washington, DC: Association of American Colleges and Universities.

Schneider, Carol Geary. 2004. "Practicing Liberal Education: Formative Themes in the Reinvention of Liberal Learning." Liberal Education 90(2): 6-11.

Schneider, Carol Geary. 2015. "The LEAP Challenge: Transforming for Students, Essential for Liberal Education." Liberal Education 101(1/2): 6-15.

Schneider, Carol Geary. 2016. "Transforming Learning: The LEAP Challenge and the Well-Being of Students." In WellBeing and Higher Education: A Strategy for Change and the Realization of Higher Education's Greater Purposes, ed. Donald Harward, 281-293. Washington, DC: Bringing Theory to Practice.

State Higher Education Executive Officers Association (SHEEO). 2017. "MSC Refinement Year September 2016 through August 2017." SHEEO. Boulder, CO: Author. Accessed July 28, 2017. http://www.sheeo.org/msc

\section{Carol Geary Schneider}

Lumina Foundation,cgs@aacu.org

Carol Geary Schneider served as president of the Association of American Colleges and Universities (AAC\&U) from 1998 to 2016 and is now a fellow with Lumina Foundation where she works on equity-minded approaches to quality learning. She coauthored Lumina Foundation's widely used Degree Qualifications Profile $(D Q P)$. While at $A A C \& U$, she designed and led the organization's long-term initiative on Liberal Education and America's Promise (LEAP), a campus action and advocacy initiative to help college students in all academic majors reap the benefits of liberal learning. She continues to write, speak, and consult about liberal education as a necessity in a globally connected democracy and an innovation-fueled economy. 